\title{
OBTENGA CAFÉ DE CALIDAD EN EL PROCESO DE BENEFICIO
}

Aída Esther Peñuela Martínez * - Juan Rodrigo Sanz Uribe **

La calidad del café colombiano se obtiene a partir de variedades de la especie arábica, en combinación con la oferta ambiental (suelo y clima), particularmente ofrecidos por la geografía y localización de Colombia, la cosecha de frutos principalmente maduros y el procesamiento por vía húmeda. Para garantizar una buena calidad de café, a partir de las condiciones mencionadas, es necesario realizar el manejo agronómico adecuado, con base en las recomendaciones de Cenicafé para la siembra, fertilización, manejo integrado de plagas, enfermedades y arvenses, y prácticas de cultivo. También es importante establecer un sistema efectivo de control en la cosecha de café de tal manera que se garantice la mejor materia prima posible.

Una vez recolectados los frutos de buena calidad, se realiza el proceso de transformación para obtener el café pergamino seco, conocido como beneficio húmedo, con el que se obtienen los cafés suaves lavados. Este proceso comprende tres etapas básicas; el despulpado, la eliminación de mucílago y el secado, con las cuales se resaltan los atributos del café colombiano y se obtienen la acidez, cuerpo medio/alto y aroma pronunciado que lo caracteriza.

\begin{tabular}{|c|c|c|c|}
\hline Genotipo & Ambientales & Agronómicos & Poscosecha \\
\hline Especie Arábica & \multirow{5}{*}{$\begin{array}{c}\text { Clima } \\
\text { Latitud } \\
\text { Altitud } \\
\text { Tipo de suelo }\end{array}$} & \multirow{5}{*}{$\begin{array}{l}\text { Ciclos de renovación } \\
\text { Fertilización } \\
\text { Sistema de producción } \\
\text { Manejo de } \\
\text { Plagas y Enfermedades } \\
\text { Manejo de arvenses }\end{array}$} & \multirow{5}{*}{$\begin{array}{c}\text { Beneficio } \\
\text { húmedo } \\
\text { Despulpado } \\
\text { Eliminación } \\
\text { del mucilago } \\
\text { Clasificación } \\
\text { Secado }\end{array}$} \\
\hline $\begin{array}{l}\text { Variedad } \\
\text { Colombia }\end{array}$ & & & \\
\hline $\begin{array}{l}\text { Variedad } \\
\text { Castillo }\end{array}$ & & & \\
\hline $\begin{array}{l}\text { Variedad } \\
\text { Cenicafé }^{8}\end{array}$ & & & \\
\hline $\begin{array}{c}\text { Variedad } \\
\text { Tabi }\end{array}$ & & & \\
\hline
\end{tabular}

Factores que determinan la calidad del café colombiano

Peñuela, A. E., \& Sanz-Uribe, J. R. (2021). Obtenga café de calidad en el proceso de beneficio. En Centro Nacional de Investigaciones de Café, Guía más agronomía, más productividad, más calidad (3a ed., pp. 189-218).

Cenicafé. https://doi.org/10.38141/10791/0014_11

ORCID

Peñuela, A. E. https://orcid.org/0000-0003-4454-9778

Sanz-Uribe, J. R. https://orcid.org/0000-0001-9875-9426 
En el proceso de beneficio se define finalmente la calidad del café, debido a que se puede mantener, siendo su objetivo principal, mejorar la calidad a través de la exaltación de atributos. No obstante, también en este proceso puede deteriorarse la calidad del producto por descuidos que conducen a la formación de defectos físicos y en taza. Por lo tanto, se hace necesario disponer de un conjunto de prácticas que deben aplicarse, con el fin de disminuir este riesgo, como se describe a continuación:

\section{FACTORES DEL PROCESO QUE INFLUYEN EN LA OBTENCIÓN DE CAFÉ DE BUENA CALIDAD}

Práctica I.

Asegure la calidad de la recolección del café

Uno de los factores más determinantes es la calidad de la recolección. Una vez el fruto ha alcanzado su desarrollo en la planta, en promedio a las 32 semanas después de la floración, presenta las características adecuadas para ser recolectado. Debido a las diferencias en el momento de floración dadas las condiciones climáticas en las diferentes zonas del país, en una misma rama se presentan frutos en diferentes estados de desarrollo, que dificultan la recolección de los frutos maduros.

Una recolección de buena calidad se caracteriza por tener más del $80 \%$ de frutos maduros y menos del $2,5 \%$ de frutos verdes. Deben evitarse también los frutos conocidos como verde-pintón, que son aquellos con apariencia amarillosa que no despulpan con la presión de los dedos, los cuales, aún en bajas proporciones, causan deterioro de la calidad generando bajas calificaciones en taza, asociadas con sabores amargos 0 astringentes.

Al inicio de la cosecha es común observar heterogeneidad en los estados de madurez del café y un elevado porcentaje de frutos secos, que afectan la calidad de la recolección. Para solucionar esta situación, es recomendable entrar al lote de café para recoger 


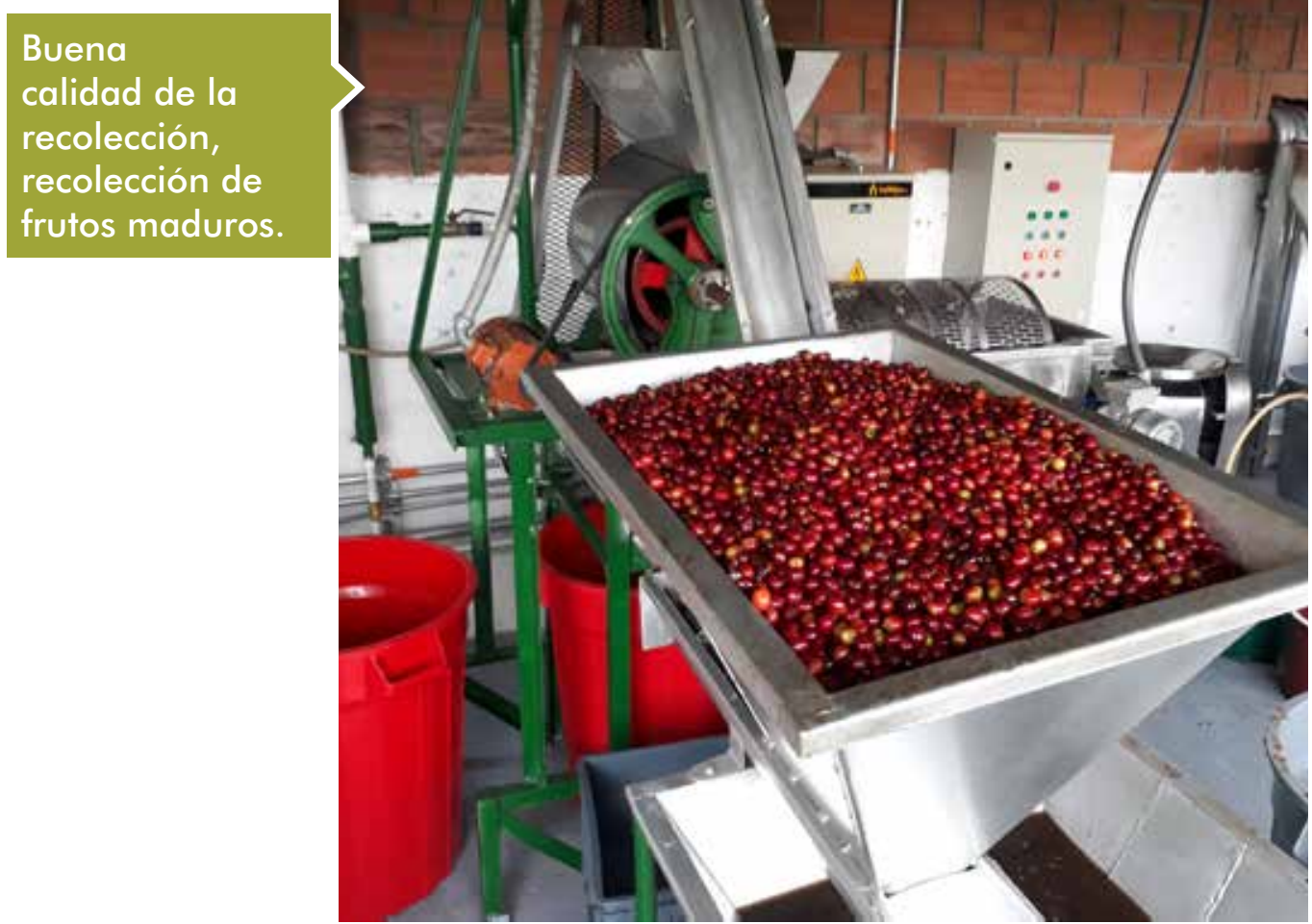

los frutos de inferior calidad y de avanzado estado de desarrollo ("descuñe"), a la espera de tener una madurez más homogénea en los siguientes pases, que facilite la recolección de los frutos cosechables y mejore la calidad de la masa cosechada.

El control de la recolección debe hacerse directamente en el campo, con el fin de corregir oportunamente el exceso de frutos verdes o pintones antes de llegar al beneficiadero. Se recomienda revisar el café recolectado en los recipientes y las estopas de los recolectores.

La manera más sencilla y rápida es mediante el uso del método Mediverdes ${ }^{\circledR}$, el cual consta de un recipiente de $600 \mathrm{~mL}$ que puede contener aproximadamente $330 \mathrm{~g}$ de frutos de café. Con este método se aceptan hasta seis frutos verdes, que corresponden a un contenido máximo de 2,5\% aproximadamente. Otros métodos que consideran menor tamaño de muestra son inexactos para determinar la proporción de frutos no deseados, como es el caso de la tabla de 


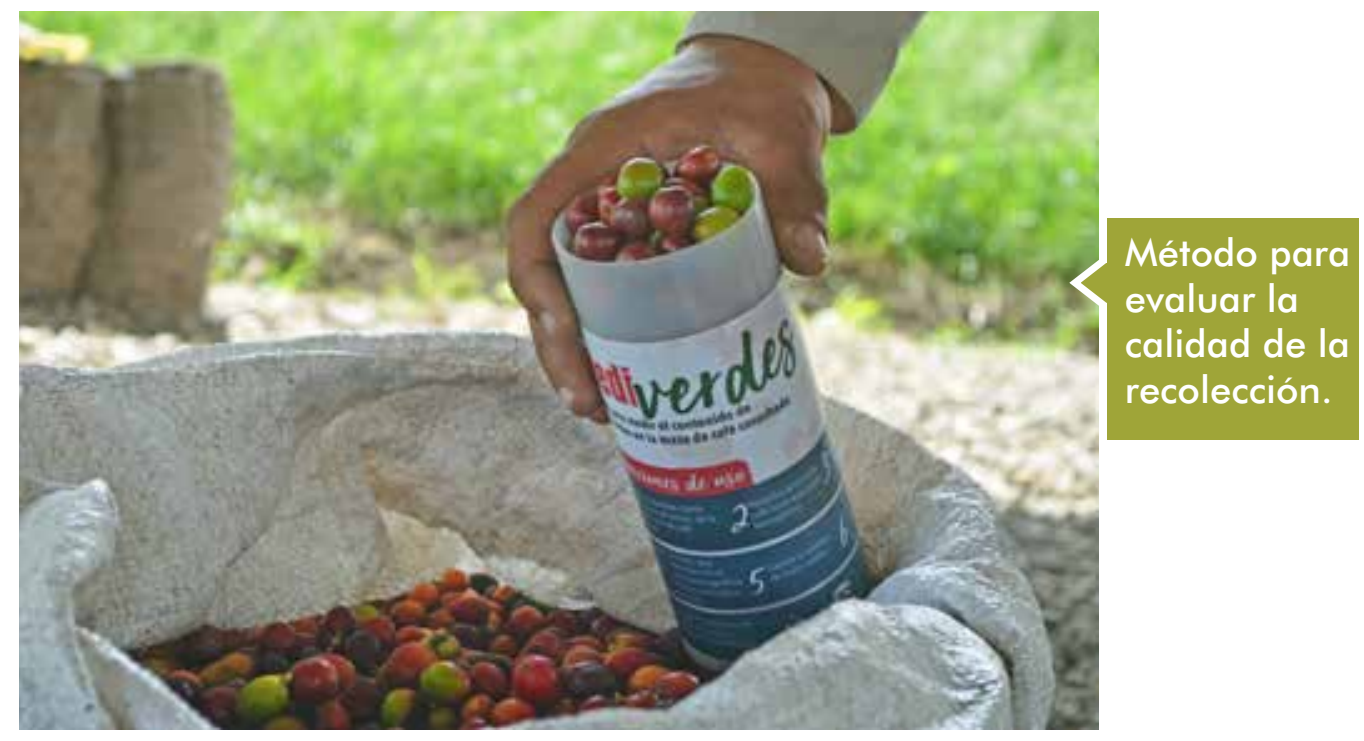

madera con cavidades para 100 frutos, con la cual podría disminuirse el error, tomando dos muestras diferentes sobre la misma masa. La suma de los frutos verdes no debe sobrepasar de siete unidades para estar en un rango aceptable.

El recipiente Mediverdes ${ }^{\circledR}$ también puede ser utilizado para la evaluación de la calidad de la recolección una vez el café es recibido en el beneficiadero y antes de comenzar el proceso.

Es muy importante para este proceso que la muestra de café sea homogénea, es decir, que no pertenezca a un solo saco o una parte de la tolva. También, que los frutos dentro del recipiente queden a ras, de modo que siempre se tenga la cantidad de café correspondiente al volumen de $600 \mathrm{~mL}$.

Para ayudar a realizar la clasificación por estados de madurez, se desarrolló la Carta de Color Cromacafe ${ }^{\circledR}$, que permite identificar fácilmente el cambio de color de los frutos de café de las variedades de cereza roja y conocer la calidad de la maduración de los frutos antes del proceso. 


\section{Asegure la calidad de la regolererión del teaft́}

Una práctica para empezar bien el proceso de beneficio del café
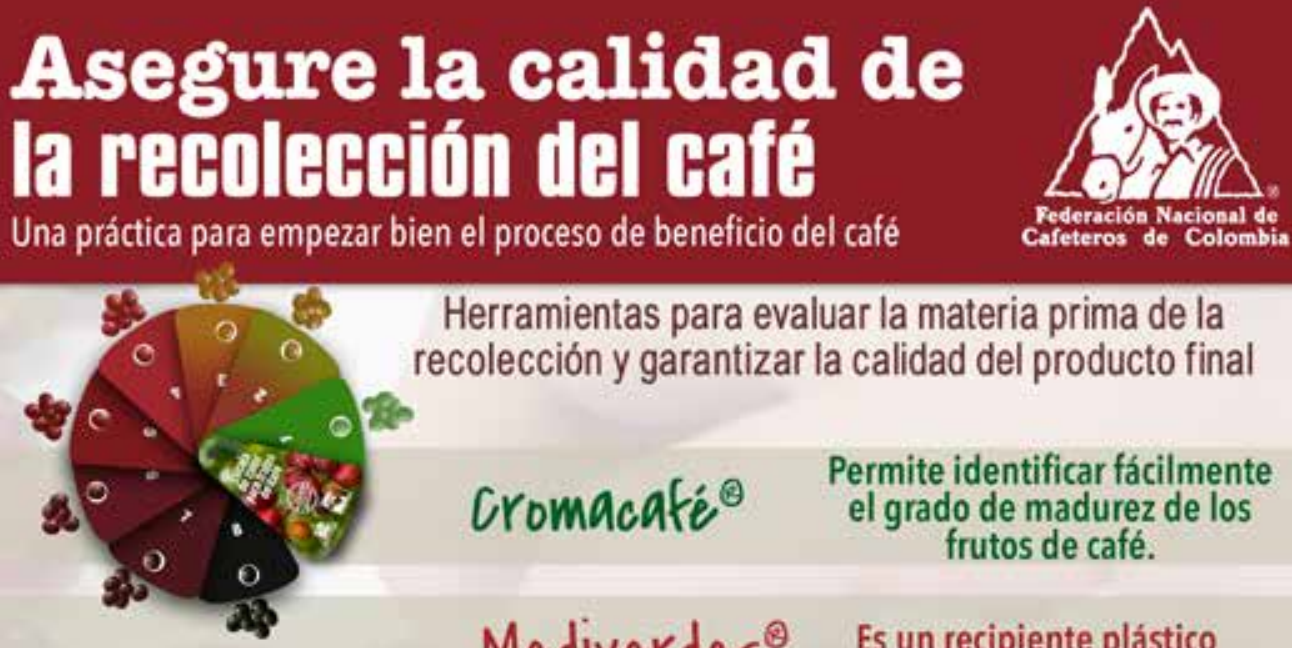

Herramientas para evaluar la materia prima de la recolección y garantizar la calidad del producto final

Cromacafé

Permite identificar fácilmente el grado de madurez de los frutos de café.

Mediverdes ${ }^{\circ}$ Es un recipiente plástico

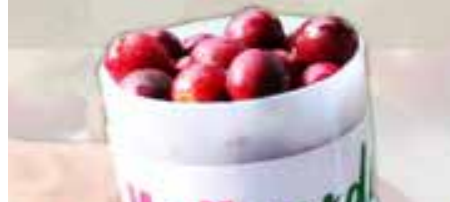
con un volumen de $600 \mathrm{~mL}$.

\section{Para garantizar la calidad de la recolección realice:}

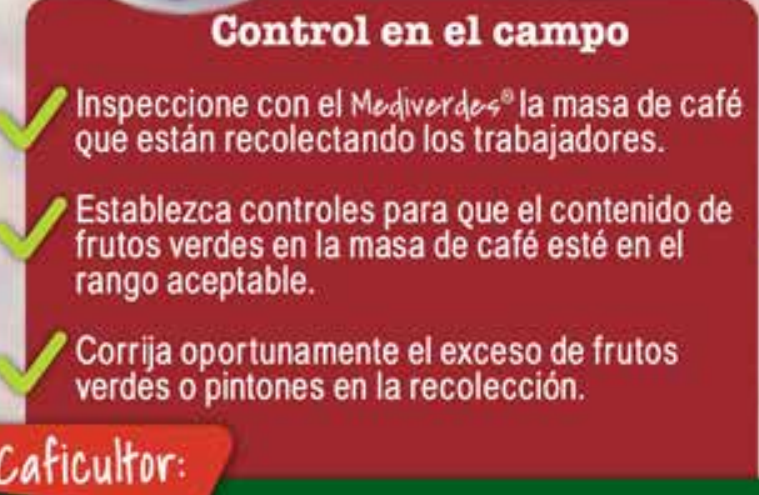

\section{Control en el campo}

Inspeccione con el Modivordo-s\% la masa de café Que están recolectando los trabajadores.

Establezca controles para que el contenido de frutos verdes en la masa de café esté en el rango aceptable.

Corrija oportunamente el exceso de frutos verdes o pintones en la recolección.

Monitoreo en la tolva

Utilice el recipiente Mediverdes. y Cromacatio $^{\circ}$ para caracterizar su materia prima en la tolva del beneficiadero.

\section{Caficulfor:}

Haga el control y monitoreo de la calidad del café recolectado antes de comenzar el beneficio de café. consulte con su Extensionista.

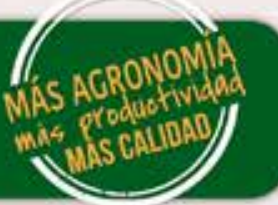




\section{Práctica 2.}

Procese cada tanda de café de manera independiente

Esta decisión garantiza que se mantenga la calidad, al no mezclar el café recolectado en tiempos diferentes. También permite hacer un mejor seguimiento al proceso ya que la calidad inicial varía de una tanda a otra, lo cual afectaría un café de buena calidad si se mezcla con otro de menor calidad.

Al realizar esta práctica se tendrán las siguientes ventajas:

$\rightarrow$ Calidad de café más homogénea, en cada tanda

$\rightarrow$ Trazabilidad en las etapas del proceso

$\rightarrow$ Consistencia en la calidad del café de diferentes tandas

$\rightarrow$ Facilidad para el seguimiento de las etapas como la fermentación haciendo uso del Fermaestro $®$ o el secado mediante el Gravimet 


\section{Procese separadamente Hadia tanda is Bafí}

Reduzca las variaciones de calidad del producto final

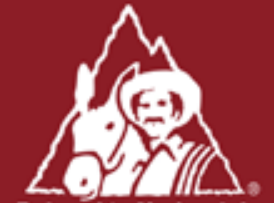

Federación Nacional de Cafeteros de Colombia

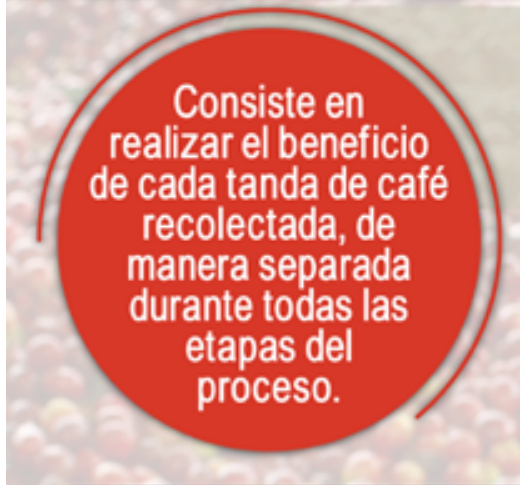

\section{¿Cómo separar las tandas de café?}

Beneficie el café recolectado en el dia, evite mezclar frutos de diferentes dias.

Si acopia café al medio dia y por la tarde despulpe cada tanda.

Si realiza fermentación, disponga un tanque Que corresponda a un momento de despulpado.

Beneficie las tandas de café de buena calidad en proceso separado de las pasillas.

Seque cada tanda de café separadamente.

\section{Caficultor:}

Para separarlas, debe tener a disposición:

- Al menos dos tanques de fermentación.

- Suficiente capacidad de secado, ya sea solar o mecánico.

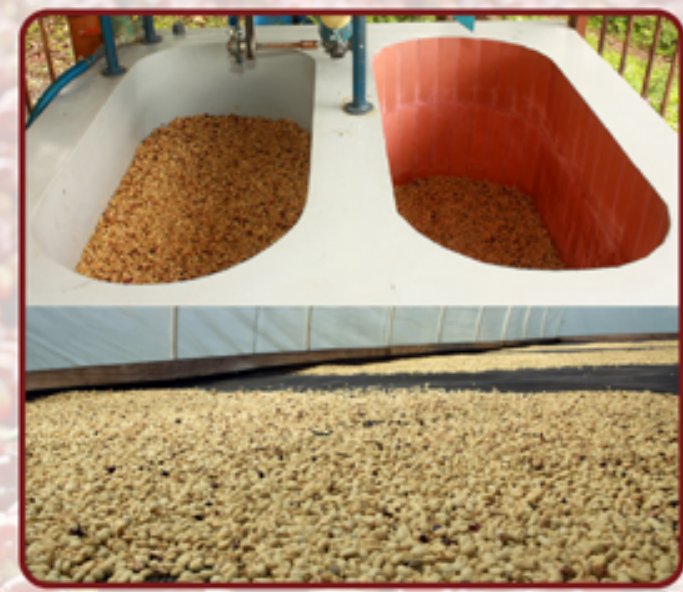

\section{Ventajas:}

Se obtiene una calidad más homogénea en cada tanda de café.

Permite realizar la trazabilidad en las etapas del proceso.

Aumenta la probabilidad de tener calidad consistente en diferentes tandas.

Permite monitorear etapas críticas como la fermentación y el secado.

Procese separadamente las tandas de café para obtener una calidad consistente del café beneficiado en su finca. consulte con su Extensionista.

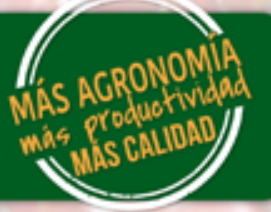




\section{Práctica 3.}

Retire frutos y granos de inferior calidad

La clasificación del café permite la separación de frutos y granos de inferior calidad para obtener un producto estable a lo largo del proceso. Aunque se haya tenido una buena recolección, es importante realizar la clasificación de los frutos, del café despulpado y del café lavado, como se explica a continuación:

\section{Clasificación hidráulica de los frutos}

Frutos de inferior calidad como secos, brocados y vanos, presentan menor densidad que el agua, por lo que la manera más eficaz de separarlos es a través de la clasificación por densidad en agua. Para lo anterior y con el ánimo de cumplir con los indicadores ambientales planteados por la ley colombiana, respecto al uso eficiente del agua, Cenicafé recomienda diferentes dispositivos de acuerdo con la cantidad de café a procesar.

Las capacidades de los dispositivos de clasificación recomendados fueron definidas con base en el día de mayor producción de la cosecha, de modo que se tienen:

- Uso de la doble caneca, para una producción menor o igual a $1.500 \mathrm{~kg}$ de frutos de café.

- Separador hidráulico de tolva y tornillo sinfín, en el modelo que le corresponda para producciones entre 1.000 y $4.000 \mathrm{~kg}$

- Tanque sifón con recirculación de agua, para producciones superiores a $20.000 \mathrm{~kg}$.

- Para producciones entre 4.000 y $20.000 \mathrm{~kg}$ en el día pico se recomienda utilizar varios separadores hidráulicos de tolva y tornillo sifón. 


\section{Clasificación del café despulpado}

Una vez el café sale de la despulpadora puede presentar frutos sin despulpar, ya que no tienen mucílago, como los verdes y secos, quedando con un mayor tamaño que los granos despulpados. Éstos se retiran fácilmente en la clasificación por tamaño, porque quedan atrapados en la parte superior de la zaranda, en caso de una zaranda plana o al interior de ella cuando se utiliza zaranda cilíndrica. En este proceso también se retiran trozos de pulpa o granos con pulpa adherida.

Existen dos factores en las zarandas que tienen influencia sobre la calidad del producto final: la forma de construcción y el ancho de las perforaciones.

Para la forma de construcción se utiliza lámina troquelada o varillas paralelas. Las primeras tienen mayor retención de impurezas debido a que tienen menor porcentaje de área perforada, por lo que el café que entra al tanque es más limpio y homogéneo. Para el ancho de las perforaciones debe tenerse en cuenta el tamaño de los granos para obtener una buena clasificación, con el uso de las variedades Castillo ${ }^{\circledR}$ y Cenicafé $1 \circledR$ se recomiendan perforaciones de $8,5 \mathrm{~mm}$ de ancho.

\section{Clasificación hidráulica del café lavado}

Una vez es obtenido el café lavado y antes de iniciar el secado debe realizarse una clasificación por densidad, con el fin de remover de la masa principal granos defectuosos como brocados o vanos, que no fueron retirados anteriormente.

Si el lavado se realiza en el mismo tanque de fermentación con la técnica de los cuatro enjuagues, se utiliza mayor cantidad de agua en el último enjuague, para que este tipo de granos floten en el agua y puedan retirarse manualmente por medio de un cedazo o colador.

Para mayores cantidades de café procesado con el uso de máquinas como el desmucilaginador mecánico - DESLIM o con el lavador del 
Ecomill ${ }^{\circledR}$, se recomienda remover los flotes restantes en un sistema de transporte con bomba sumergible, con recirculación de agua.

\section{Sistemas de clasificación de frutos y granos de inferior calidad}

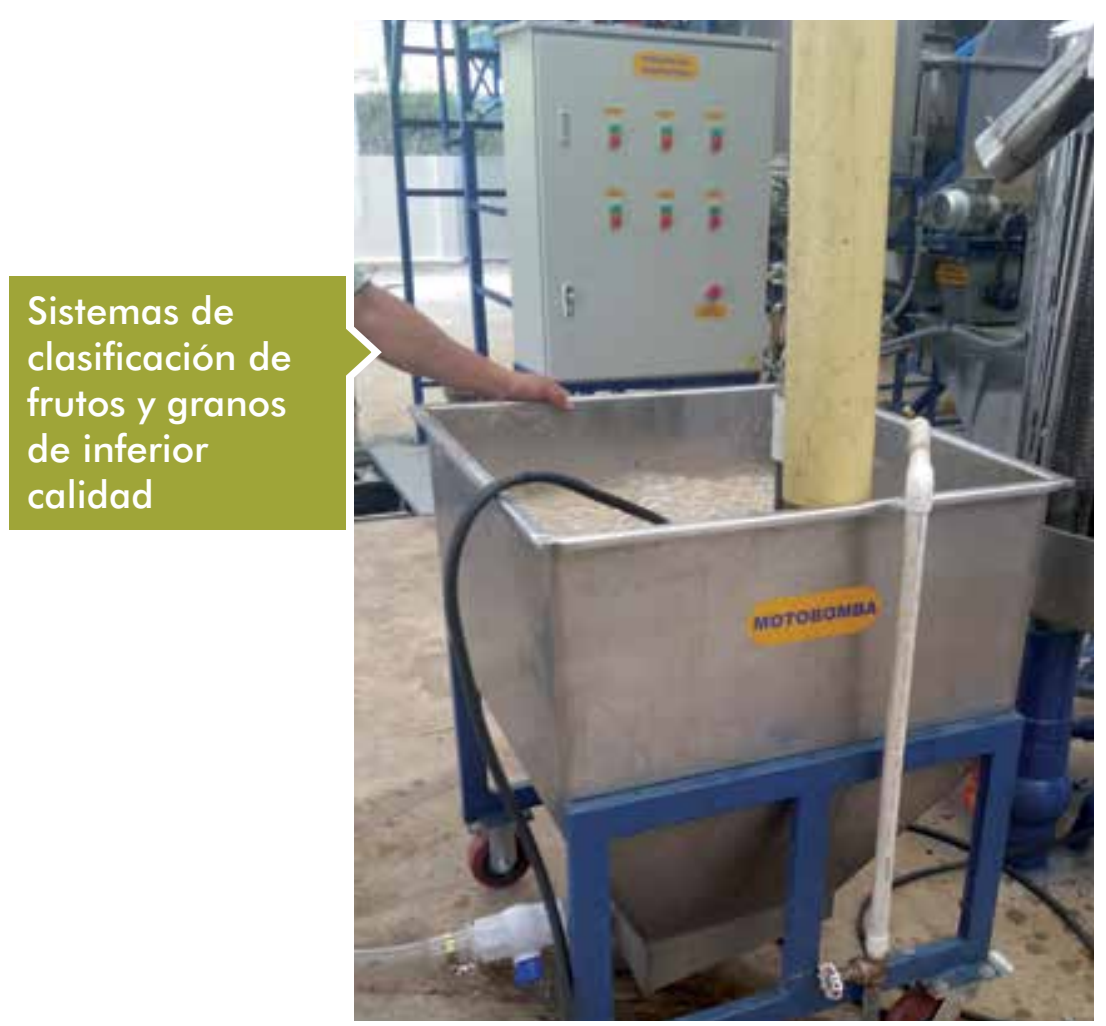




\section{Retire frutos y granos de inferior tealidad}

Una práctica para mejorar el factor de rendimiento y la calidad del café

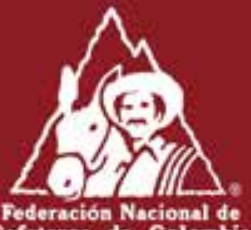
Cafoteros de Colombin

Consiste en retirar la mayor parte de granos con defectos, en diferentes momentos del proceso
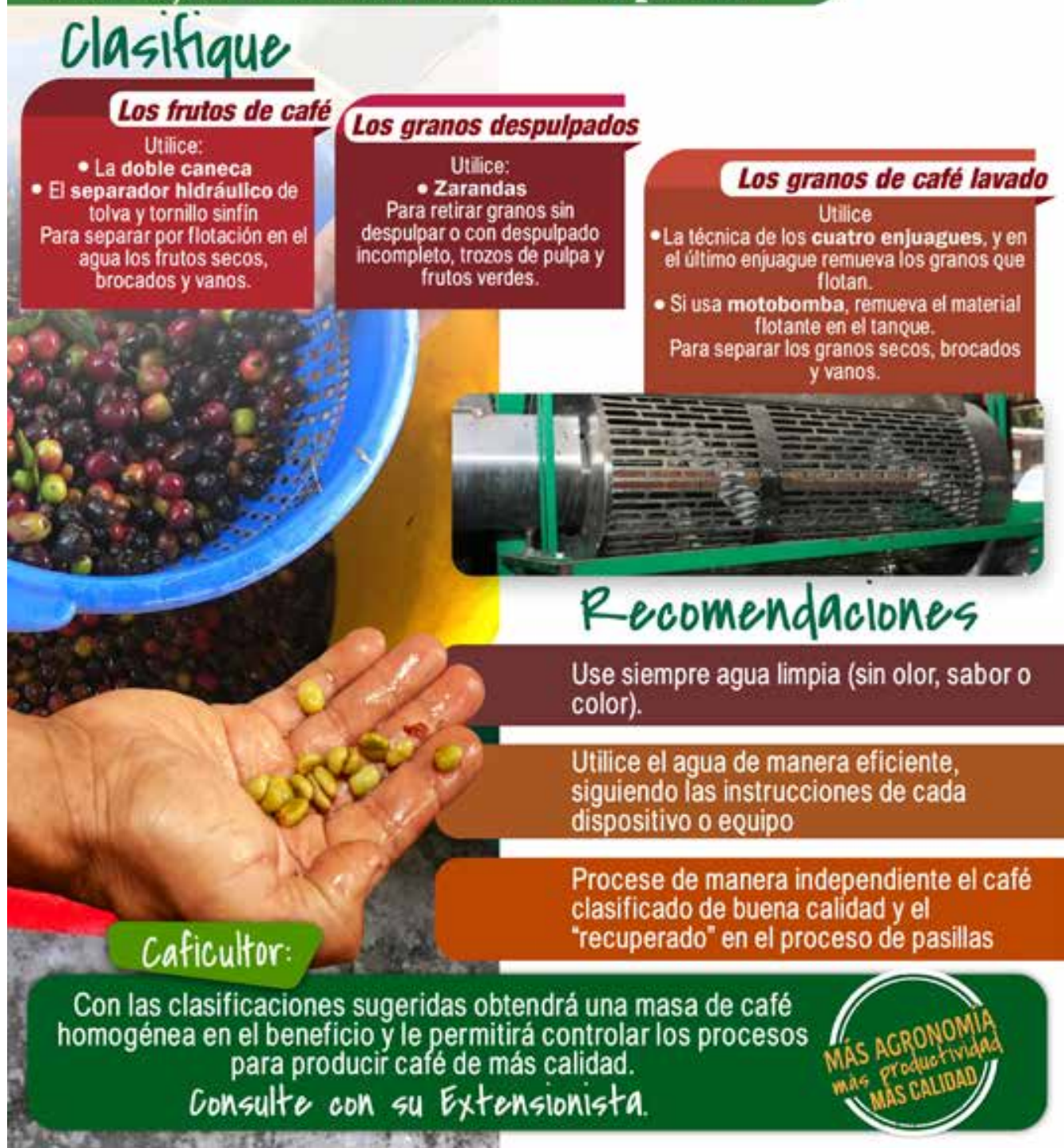


\section{Práctica 4.}

Realice el mantenimiento, limpieza y calibración de la despulpadora y demás equipos del proceso

\section{Etapas del proceso húmedo}

Las principales etapas del proceso húmedo son el despulpado, la remoción de mucílago y el secado, en las que existen diferentes tipos de equipos que están en contacto con el café, por lo que se recomienda mantener el buen estado de las máquinas utilizadas para las diferentes etapas, respecto a limpieza y funcionamiento mecánico con el fin de obtener su mejor desempeño. Deben realizarse los mantenimientos preventivos y de aseo con agua limpia cada vez que se utilicen.

En cada una de estas etapas debe considerarse lo siguiente:

\section{Despulpado}

Esta etapa debe hacerse sin adición de agua, además para que el café despulpado obtenido esté dentro de los valores indicados en la NTC-2090, es necesario considerar lo siguiente:

> Verificar el funcionamiento del equipo, de manera que obtenga la capacidad estipulada por el fabricante de la máquina (en $\mathrm{kg} / \mathrm{h}$ ), registrando el tiempo requerido para el despulpado, con la cantidad inicial de la masa de frutos de café.

- Verificar que los dientes de la camisa se encuentren en buen estado, sin daños o deformidades que afecten la calidad del despulpado.

- Calibrar la separación entre el pechero de la despulpadora y la camisa del cilindro de acuerdo con el tamaño de los frutos, para evitar pérdidas de granos despulpados en la pulpa o gran cantidad de granos mordidos. 
La calidad del despulpado se evalúa tomando cinco muestras de $60 \mathrm{~g}$, para determinar los siguientes indicadores descritos en la Norma Técnica Colombiana 2090:

b Grano mordido: grano que presenta ruptura de la almendra por acción de los dientes de la camisa, no debe ser mayor a $0,5 \%$.

- Grano trillado: grano que presenta pérdida de más de la mitad de su pergamino por acción de los dientes de la camisa, no debe ser mayor a 0,5\%.

- Pulpa en el café despulpado: trozos de pulpa que pasan a la masa de café, no debe ser superior al $2,0 \%$.

$\rightarrow$ Frutos sin despulpar: frutos que conservan la cáscara o pulpa después de haber pasado por la máquina e ingresan a la masa de café despulpado, no debe ser superior al 1,0\%.

$\rightarrow$ Granos despulpados en la pulpa: no debe haber granos en la pulpa, ya que esto representa pérdidas económicas. Para esta determinación deben tomarse cinco muestras de $200 \mathrm{~g}$ del material a la salida o descarga de pulpa de la máquina, se extraen los granos de café y se determina la masa total de granos en $1.000 \mathrm{~g}$ de muestra.

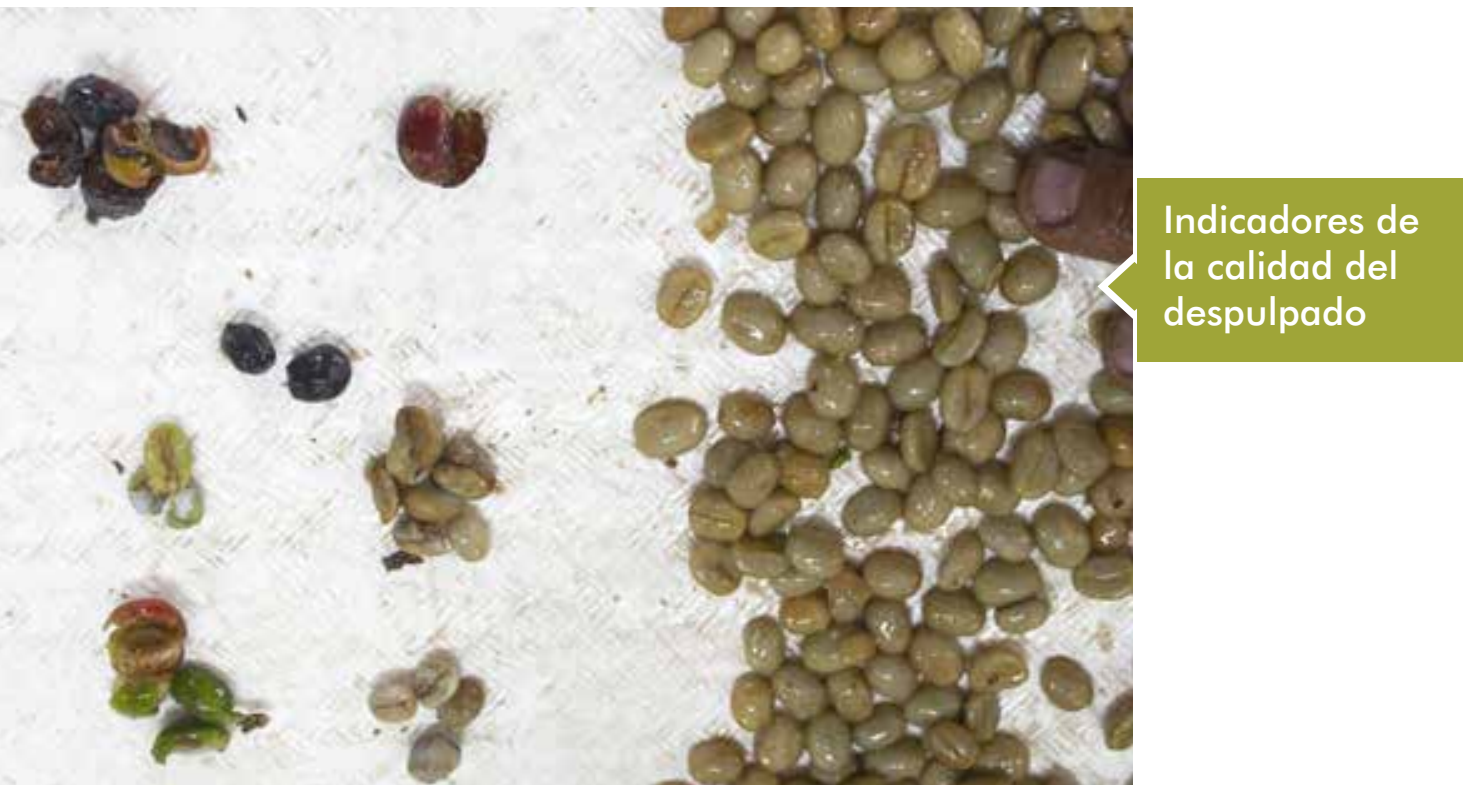




\section{Iimpie y calibre Ios equipos para el beneficio}

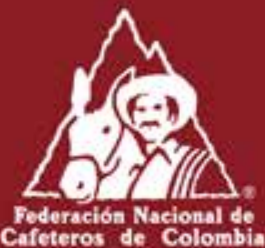

Una práctica para evitar granos con defectos físicos Que dañan la calidad del café

Consiste en obtener el mejor desempeño de las máquinas a través de las etapas del proceso como la clasificación, despulpado, remoción de mucílago, lavado y secado del café

Verifioue el estado de la despulpadora.

Lubrique todas las partes móviles de la despulpadora (chumaceras, eje alimentador, pinones).

Calibre la despulpadora, tome una muestra de café despulpado e identifique la presencia de granos mordidos o trillados.

Al finalizar la jornada de trabajo, limpie y organice ol beneficiadero.

Después de cada jornada limpie los residuos de pulpa, mucilago o granos de cafe en los equipos.

Si tiene equipos como desmucilaginador o lavador mecanico, verifique que todas sus partes esten ajustadas, limpias y engrase sus rodamientos.

Si tiene secador mecánico verifique Que el ventilador y el intercambiad or no tengan fugas de aire o gases de combustión que contaminen el café.

\section{Caficultor:}

Realice el mantenimiento preventivo y aseo de los equipos del proceso de beneficio

consulte con su Extensionista.

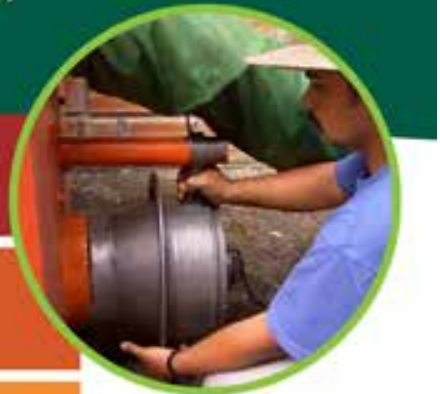




\section{Despulpado del batt}

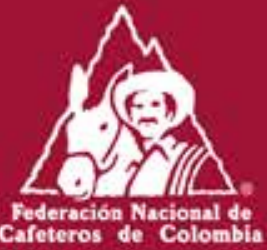

\section{Las despulpadoras son equipos que están en \\ contacto con cada uno de los granos que se producen \\ en la finca.}

No se debe utilizar agua en el despulpado, ya que el fruto contiene la súficiente para pasar por la máquina.

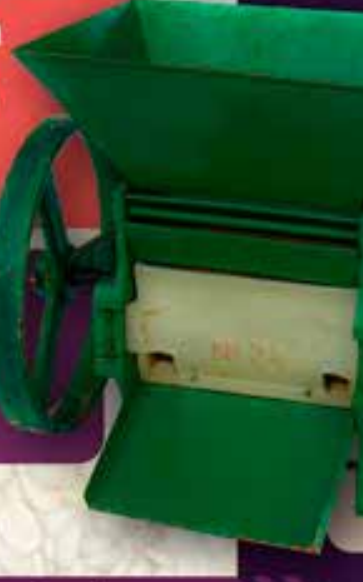

La etapa despulpado se requiere para separar la cáscara (pulpá) de los granos de café.

\section{Principio de Funcionamiento}

\section{Norma Téeniera Eolombiana 2010}

$\begin{array}{lll}\text { Proporción } & \text { Proporción } & \text { Proporción } \\ \text { de pulpa en } & \text { de granos } & \text { de jranos } \\ \text { el grano } & \text { sin } & \text { mordidos en } \\ \text { debe ser } & \text { despulpar } & \text { el cafe } \\ \text { menor que } & \text { menor del } & \text { despulpado } \\ \mathbf{3 , 0 \%} & \mathbf{1 , 0 \%} & \text { menores del } \\ \end{array}$

\section{Cafioultor:}

Para que las despulpadoras trabajen adecuadamente es conveniente realizar una clasificación por densidad antes de esta etapa.

Despulpadoras de café

Proporción de franos

trillados en Cero granos

el caré

despulpado

menores

del $0,5 \%$

\section{sanos en $1 \mathrm{a}$}

pulpa

Calibre y mantenga la despulpadora en buen estado y aseada, para no causar daño mecánico, ni contaminación cruzada a los granos de café. consulte oon su Extensionista.

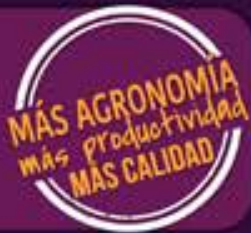




\section{Calibración de la despulpadora}

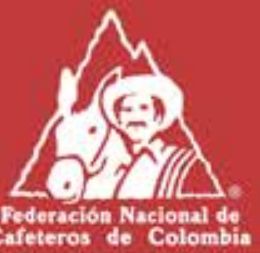

E1 despulpado

us una etapa principal en el beneticio del cafie, el equipo en buen estado de funcoonamiento permite mantener la calidad del café

Para frutos grandes el pechero se aleja.

Para frutos pequeños el pechero se acerca.

Si la proporción de pulpa en el grano es mayor que la aceptable, debe acercarse el pechero al cilindro.

Si la proporción de granos sin despulpar es mayor que la aceptable, el pechero debe acercarse al cilindro.

Si los granos mordidos y trillados superan los limites aceptables, el pechero debe alejarse del cilindro.

Si hay presencia de granos sanos én la pulpa, el pechero debe acercarse.

\section{caficultor:}

Con una máQuina despulpadora en buen estado evita defectos físicos en el café y pérdidas económicas

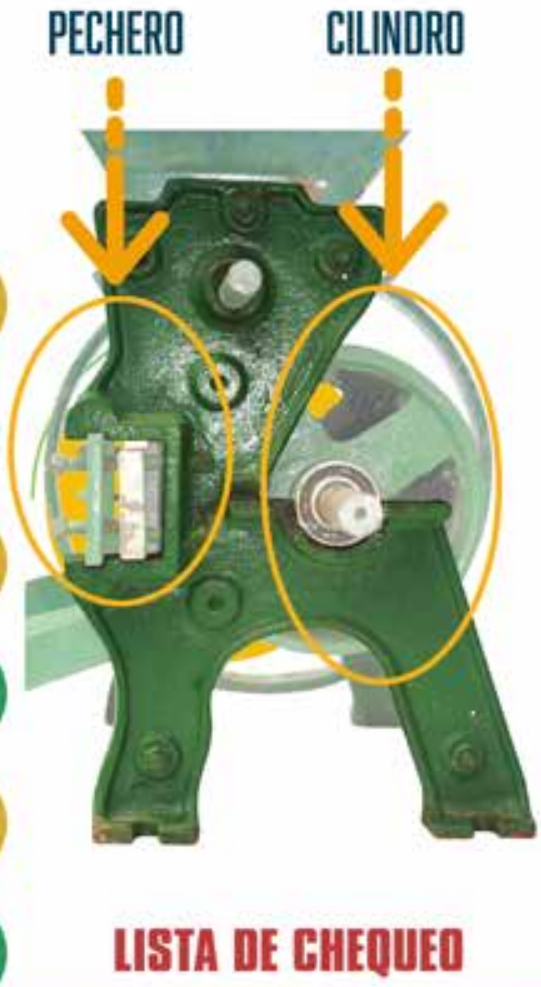

La capacidad de la despulpadora corresponde con la recomendada por el fabricante

La velocidad de giro corresponde con la recomendada por el fabricante

Los rodamientos o bujes están en buen estado

La camisa de la despulpadora está bien instalada y en bueri estado 


\section{Eliminación del mucílago}

La eliminación del mucílago del café puede hacerse de diferentes maneras. Una forma consiste en degradar el mucílago con fermentación natural y posterior lavado, el cual es el método más usado. También puede retirarse de manera mecánica mediante el desmucilaginador mecánico DESLIM, o pueden usarse enzimas pectinolíticas para degradar el mucílago más rápidamente antes de lavarlo. También puede usarse el sistema Ecomill@ que se utiliza para lavar mecánicamente y con muy poca agua, el café que pasa por fermentación natural o cuyo mucílago fue degradado con enzimas.

\section{Eliminación mecánica del mucilago}

Cenicafé desarrolló el equipo de desmucilaginado mécanico Deslim para remover el mucílago del café recién despulpado, en porcentajes mayores al $98 \%$. El equipo Deslim debe garantizar un buen funcionamiento y estar sincronizado con la capacidad de la despulpadora, de modo que no altere la calidad física y sensorial del café. Con este sistema, el daño mecánico del producto se presenta en casos en los cuales la cantidad de café despulpado que ingresa al desmucilaginador es menor a la capacidad del mismo, ocasionando mayor tiempo de retención de los granos dentro del equipo. También existen problemas de calidad del café cuando se sobrealimenta el equipo, porque se presenta eliminación incompleta de mucílago, que aumenta el riesgo de deterioro en etapas posteriores.

El equipo debe tener un sistema para controlar el consumo de agua, de tal manera que sea el especificado, entre 0,7 y $1,0 \mathrm{~L} / \mathrm{kg}$ de café pergamino seco. Esta calibración debe hacerse frecuentemente para que se garantice el control de más del $90 \%$ de la contaminación producida por las aguas residuales de café, cuando se mezclan con la pulpa.

$\rightarrow$ Al dejarse el desmucilaginador cargado con café a la espera de un nuevo lote a procesar, junto con una mala calibración de la capacidad del equipo, se generan manchas oscuras en la almendra del café, conocido comúnmente como "grano tigre" que afectan la apariencia física y la calidad. 
- Dado que el desmucilaginador mecánico genera grandes esfuerzos sobre la masa de café despulpado, no se recomienda aprovechar esta característica para "recuperar" los frutos denominados guayabas y medias caras (café con pulpa adherida), con el fin de convertirlos en café aparentemente bueno. Esta práctica tiene influencia negativa sobre el sabor de la taza de café, contribuyendo con sabores astringentes.

\section{El Desmucilaginador mecánico Deslim requiere de algunas} prácticas de mantenimiento para que haya un funcionamiento adecuado.

$\rightarrow$ En primera instancia debe tenerse cuidado que la máquina tenga la capacidad nominal del desmucilaginador, en una aproximación de más o menos $10 \%$.

$\rightarrow$ El rotor del equipo está soportado por rodamientos, de los cuales el inferior es de mayor cuidado. Hay que mantener lubricados los rodamientos con grasa multipropósito, al menos cada mes.

$\rightarrow$ Se debe tener cuidado que en el interior no aparezcan filos que puedan dañar los granos.

$\rightarrow$ Si el desgaste de los agitadores es muy grande, cosa que sucede cada tres o cuatro años, deben invertir la posición, para que duren otro tiempo igual.

$\rightarrow$ Cuando los dos lados de los dientes estén desgastados deben cambiarse los agitadores por otros nuevos.
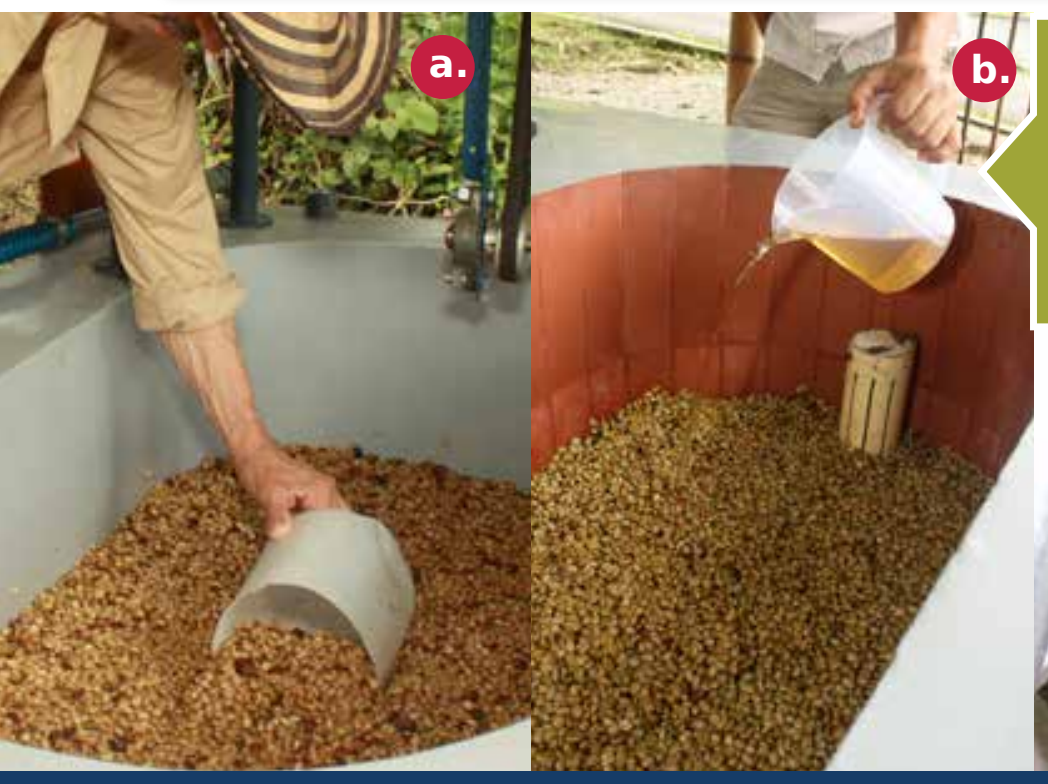

Diferentes métodos de eliminación de mucílago. a. Fermentación natural; b. Adición de enzimas pectinolíticas; c. Equipo Deslim. 
- El tope de la hélice del tornillo sinfín interior está sometido a un mayor esfuerzo, lo cual, por las características abrasivas del café, recibe mayor desgaste manifiesto en un filo que causa daños a los granos de café. Se debe revisar que esto no suceda.

\section{Lavado mecánico del café}

El equipo lavador hace parte del módulo Ecomill ${ }^{\circledR}$ viene con un diseño en dos versiones: vertical y horizontal. En los sistemas verticales $(500,1.500$ y $3.000 \mathrm{~kg} / \mathrm{h}$ de café lavado), los cuales son de flujo ascendente, el lavado se da en contracorriente, para hacer mejor aprovechamiento del agua, por lo cual tiene un consumo específico de agua promedio de $0,5 \mathrm{~L} / \mathrm{kg}$ de café pergamino seco. Con ese bajo consumo de agua se logra tener un mucílago altamente concentrado que puede ser mezclado con la pulpa, para un control del $100 \%$ de la contaminación por aguas de lavado. En la versión horizontal, el Ecomill ${ }^{\circledR} \mathrm{LH} 300$, de $300 \mathrm{~kg} / \mathrm{h}$ de café lavado, el flujo de agua es transversal, por eso tiene un $20 \%$ mayor de consumo de agua, respecto a la versión vertical, el mismo desempeño ecológico cuando se mezclan el mucílago y la pulpa.

Como cada uno de estos equipos tiene su propio dosificador de café, por lo que no es necesario hacer calibración del flujo de café, lo garantiza el correcto tiempo de retención. Por esta razón, el mantenimiento de estos equipos se compone principalmente de las siguientes prácticas:

En los equipos verticales el rotor del equipo está soportado por rodamientos, de los cuales el inferior es de mayor cuidado. Hay que mantener lubricados los rodamientos con grasa multipropósito, con frecuencia mensual.

- En los equipos horizontales el rotor está soportado sobre rodamientos ubicados en el exterior, lo que hace más fácil su mantenimiento, especialmente su lubricación con grasa multipropósito.

$\rightarrow$ Se debe realizar inspección al tacto, con una periodicidad mensual, para examinar y corregir la aparición de filos que puedan dañar los granos. 
$\rightarrow$ Si el desgaste de los agitadores es muy grande, se debe invertir la posición de ellos para que duren otro tiempo igual.

$\rightarrow$ Cuando los dos lados de los dientes estén desgastados se deben cambiar los agitadores por otros nuevos.

\section{Práctica 5.}

Monitoree la fermentación con el Fermaestro[3

Si realiza la fermentación natural, como método de eliminación de mucílago, es necesario realizar controles básicos sobre su desarrollo con el fin de evitar la formación de granos vinagres y defecto fermento. Se debe considerar lo siguiente:

> La calidad del café obtenido por fermentación depende de las condiciones en que se realizaron las etapas de recolección, clasificación y despulpado, que permiten tener una masa de café homogénea $y$, por lo tanto, puede realizarse una fermentación adecuada, ya que se han reducido los factores externos que intervienen en el desarrollo de la misma.

$\rightarrow$ El principal aspecto a controlar en la fermentación es la finalización de la misma o "punto de lavado", el cual puede variar dependiendo principalmente de las condiciones del ambiente o de la calidad de la masa de café. Para esto se utiliza el método Fermaestro ${ }^{\circledR}$ que identifica el punto de lavado cuando hay una remoción de mucílago superior al 95\%, permitiendo finalizar este proceso de forma segura para la calidad, además de realizar un lavado más eficiente.

También pueden adicionarse enzimas pectinolíticas como método de remoción de mucílago, especialmente para disminuir el tiempo de proceso respecto a la fermentación, útiles en pico de cosecha y cuando hay necesidad de aumentar la capacidad de los tanques de procesamiento. Para realizar esta labor adecuadamente debe tenerse en cuenta: 
> Utilizar la cantidad de enzima recomendada, de acuerdo con la cantidad de café cereza o café despulpado, para realizar la remoción de mucílago en un tiempo máximo de tres horas.

- Disolver la cantidad de enzima estimada de acuerdo con la cantidad de café despulpado o café cereza, en un recipiente con agua limpia, a razón de $100 \mathrm{~mL}$ de agua por cada mililitro $(\mathrm{mL})$ de enzima, aplicar directamente sobre la masa de café y agitarla para permitir el contacto del producto con los granos de café.

> Al igual que en la fermentación natural, debe controlarse el tiempo de proceso utilizando el método Fermaestro ${ }^{\circledR}$, para el cual debe tomarse la muestra de café despulpado una vez se haya aplicado la enzima. 


\section{Monitoree la fermentación con Fermacstro ${ }^{\circ}$}

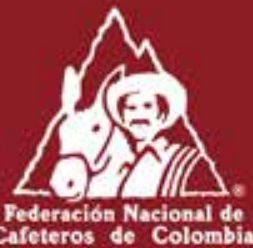

Una práctica para identificar correctamente el punto del lavado del café

Consiste en realizar el
seguimiento de la
fermentación con el fin de
evitar defectos como granos
vinagres y fermento.

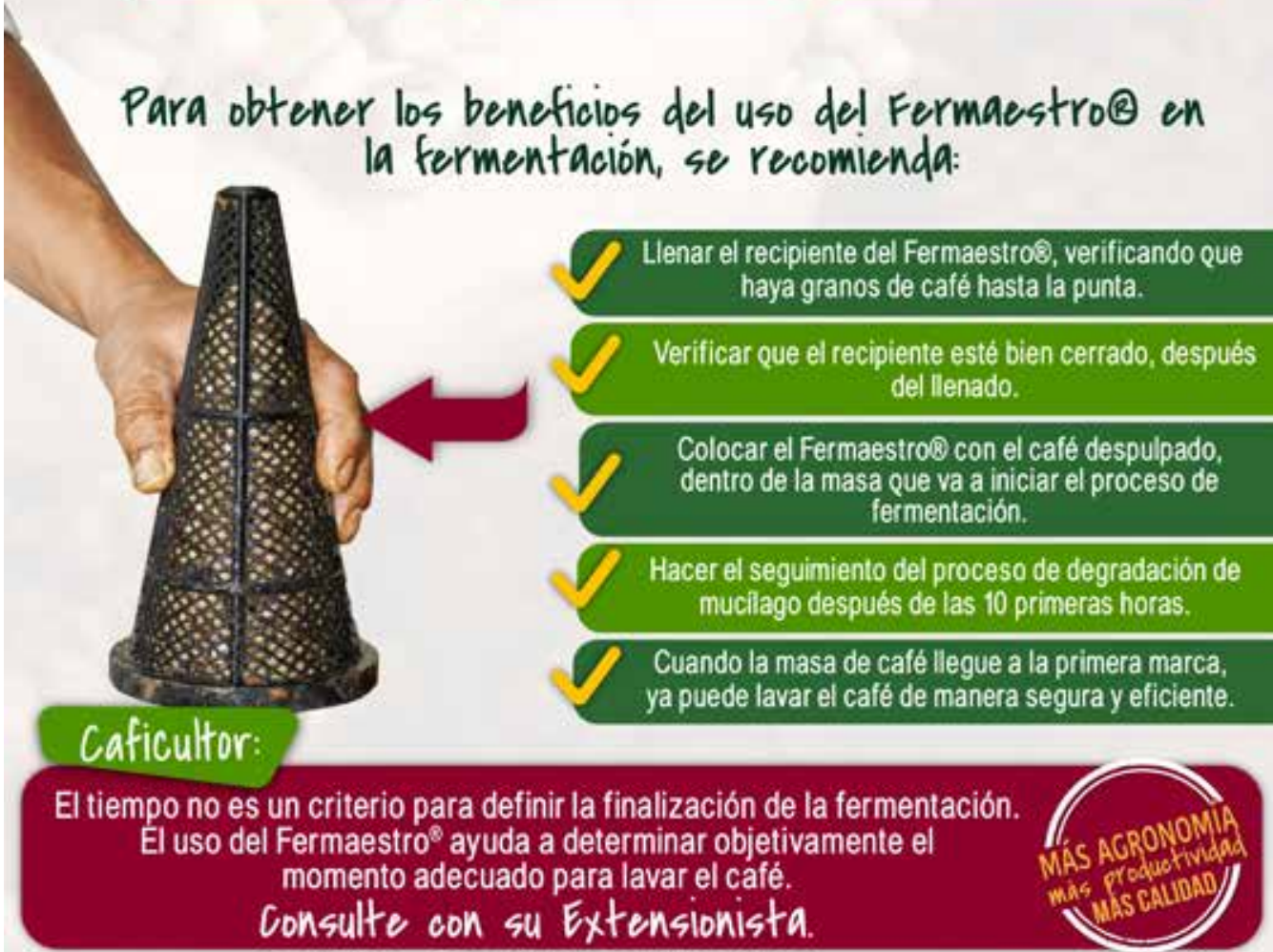




\section{Práctica 6.}

Retire el mucilago realizando un buen lavado

\section{Lavado}

Esta labor se realiza para retirar del grano de café el mucílago degradado en la etapa anterior. Puede hacerse en el mismo tanque de fermentación, aplicando la técnica de los cuatro enjuagues, agitando vigorosamente la masa con una paleta plástica, o para mayores cantidades de café, a través del lavador mecánico que hace parte de la tecnología Ecomill ®. La importancia de esta práctica radica en evitar la contaminación cruzada de los granos. Siempre debe utilizarse agua limpia para el lavado, es decir, aquella que, según los sentidos, vista, olfato y gusto, sea transparente (incolora), insabora e inolora.

En esta etapa es importante retirar la mayor cantidad de mucílago degradado, de modo que el café quede limpio, sin restos de mucílago que pueda ocasionar sabores indeseables y defectos de calidad en el café.

Para cumplir con la legislación ambiental debe utilizarse el nivel de agua sugerida para cada enjuague, cuando el lavado se realiza en el mismo tanque, o calibrar el flujo de agua según las recomendaciones de uso del Ecomill $\circledast$. El agua residual generada de este proceso debe ser tratada antes de verterla a las corrientes de agua, en el caso de utilizar la técnica de los cuatro enjuagues o adicionarla a la pulpa para facilitar su descomposición, siguiendo las recomendaciones para el manejo de los subproductos en el caso del Ecomill $\circledast$.

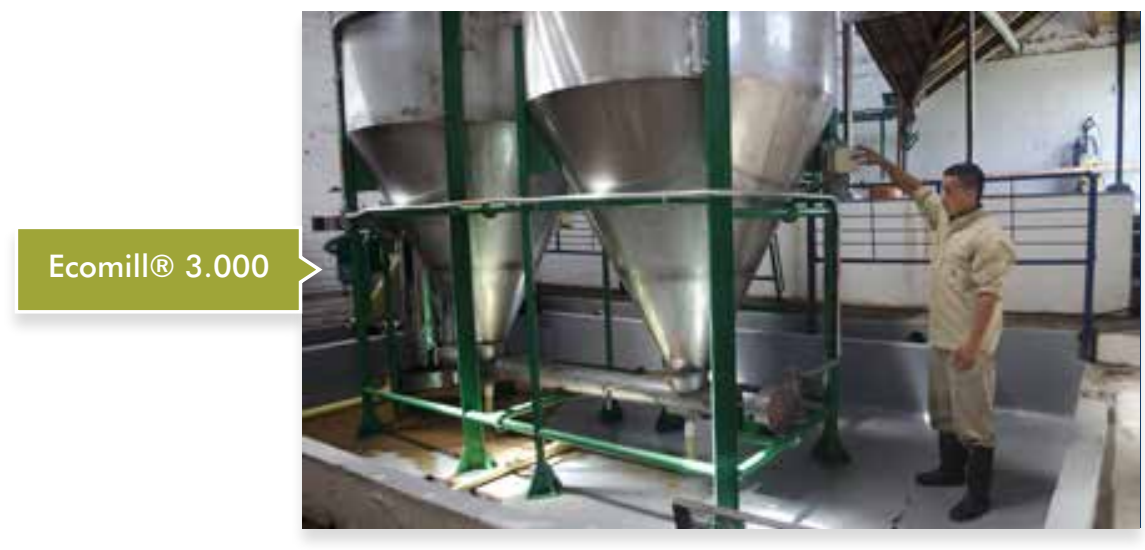




\section{Retire el mucilago reatizando un huen lavado}

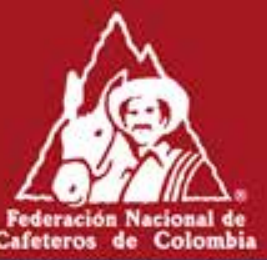

Una práctica para disminuir el riesgo de deterioro de la calidad del café

\section{Consiste realizar el lavado para retirar \\ la mayor cantidad de mucilago degradado, para evitar sabores indeseables y defectos en taza}

\section{Recomendaciones:}

Si el café proviene de la fermentación, verifique previamente el punto de lavado con el Fermaestro

Use agua limpia, es decir, Que sea transparente (incolora), insabora e inolora.

Utilice el nivel de agua sugerido técnicamente para cumplir con la legislación ambiental.

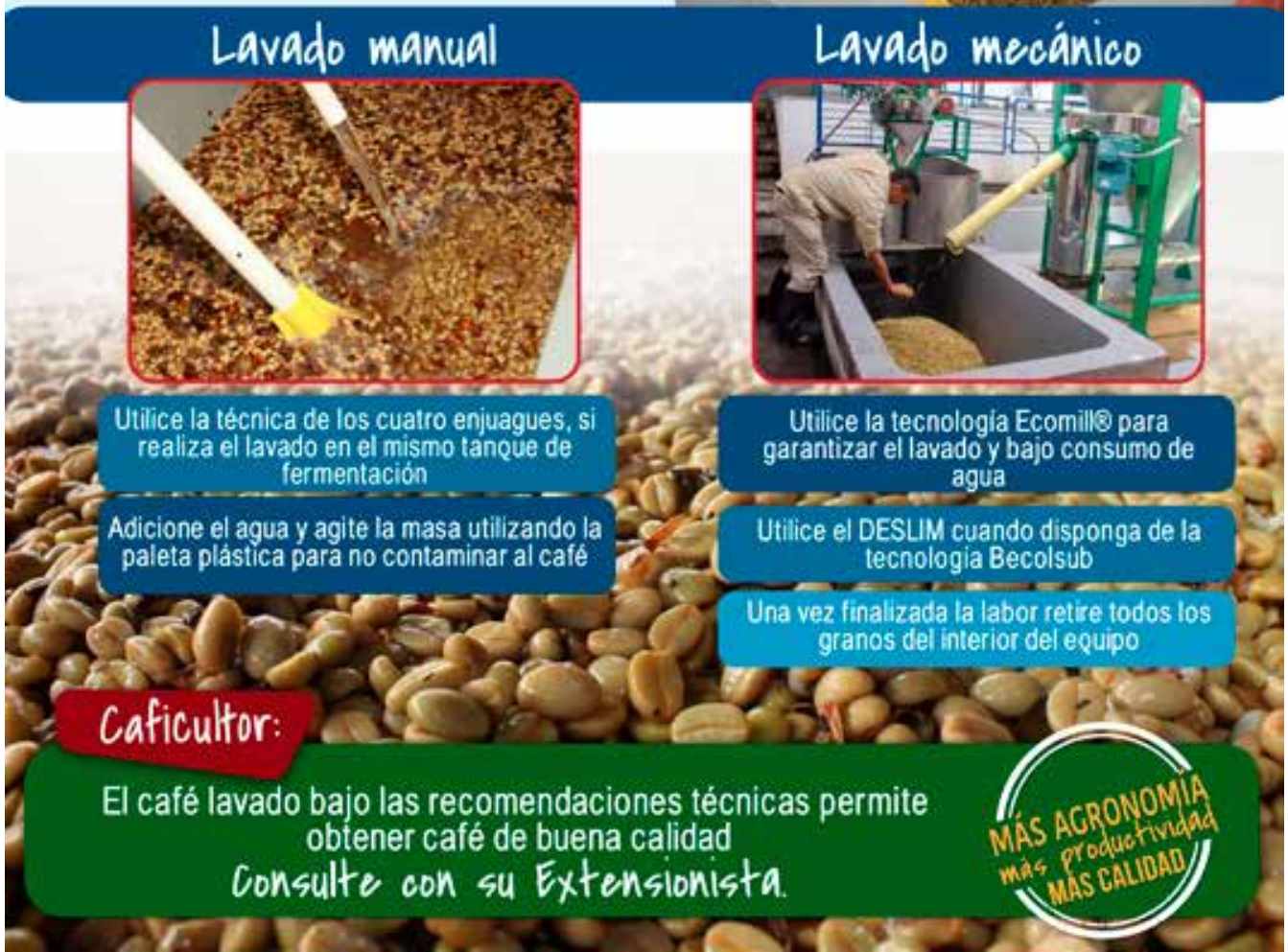


obtenga y mantenga el café pergamino seco con humedad entre el $10 \%$ y $12 \%$

\section{Secado}

Es la principal etapa de conservación de la calidad del café, ya que al disminuir el contenido de humedad del grano se reduce su actividad fisiológica y la de microorganismos que deterioran sus atributos e inocuidad. Además, mantiene la estabilidad del producto durante el almacenamiento, empaque y transporte hasta su consumo. Se recomienda iniciar este proceso preferiblemente después de haber escurrido el café.

Existen dos métodos usados para realizar este proceso, secado natural aprovechando la energía del sol y del aire ambiente, o de manera mecánica utilizando un ventilador para pasar aire caliente a través de la capa de café. Las recomendaciones para los dos métodos son las siguientes:

\section{secado solar}

Para el mejor aprovechamiento y distribución uniforme de la radiación del sol, el secador debe estar orientado en sentido Norte - Sur, libre de sombras generadas por árboles o construcciones cercanas.

El secador debe revisarse periódicamente. La cubierta plástica no debe tener perforaciones que permitan el paso de agua y debe limpiarse solamente con agua limpia, para eliminar la suciedad originada por polvo que obstaculiza el paso de la luz. El piso del secador debe ser plano y homogéneo, para evitar diferentes alturas de capa que causen desuniformidad en la humedad del café.

Cuando el secador tiene cortinas o compuertas, al inicio del secado se debe dar acceso a la circulación de aire al interior para permitir la extracción de aire húmedo y obtener la disminución de la humedad en el grano.

Para lograr un café con humedad entre el $10 \%$ y $12 \%$ con mayor exactitud, debe monitorearse desde el principio del proceso, haciendo 
uso del Método Gravimet, siguiendo las recomendaciones para lograr los mejores resultados.

Para tener un secado más eficiente y lograr mayor uniformidad de la humedad en el café debe utilizarse una capa máxima de café lavado de $2,5 \mathrm{~cm}$ de altura y revolver el café en proceso de secado mínimo cuatro veces en el día.

\section{secado mecánico}

Los cuatro parámetros clave para realizar el mejor aprovechamiento del secado mecánico son: la temperatura y el flujo del aire de secado, la altura de capa de café dentro del secador y el control de la humedad del café.

La temperatura de secado debe ser inferior a $50^{\circ} \mathrm{C}$, debido a que el grano empieza a cambiar su estructura hasta que se vuelve cristalino, generando el defecto cristalizado que daña la calidad en las pruebas de taza. El caudal de aire óptimo desde el punto de vista energético, es de $0,1 \mathrm{~m}^{3} / \mathrm{min}-\mathrm{kg}$ de café pergamino seco.

En los secadores de tres capas, la altura ideal para cada capa es de $0,25 \mathrm{~m}$, mientras que, para secadores de dos capas, con inversión de dirección del aire, se recomienda una altura máxima de 0,35 $\mathrm{m}$ por capa.

Independiente del sistema de secado, la humedad del café debe estar entre el $10 \%$ y el $12 \%$. Para la determinación exacta, fácil, sencilla y económica de la humedad del grano Cenicafé desarrolló el método Gravimet, el cual tiene adaptaciones para el secado solar y el secado mecánico, dependiendo de la masa original, la cual debe estar compuesta únicamente por granos sanos. Este método permite disminuir el error obtenido cuando se utilizan métodos subjetivos como el color de la almendra y la dureza o resistencia al corte, y también la disminución de costos ante el uso de equipos determinadores de humedad electrónicos, que tienen limitaciones al momento de la medición directa, pues requieren una muestra con humedad y temperatura uniforme, lo cual toma más de 30 minutos en estabilizarse. 


\section{Obtenga y mantenga eaffeperyamino seec entre el $10 \%$ y $12 \%$ de humedad}

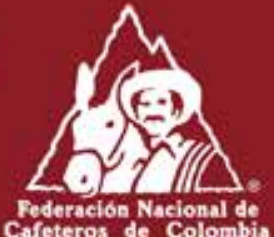

Una práctica para obtener un café estable hasta su consumo final

Consiste en realizar el secado

adecuadamente para obtener café en el rango de humedad comercial y evitar franos sobresecos oflojos.

secado solar

Use Gravimet

Altura de capa máxima y uniforme de $2,5 \mathrm{~cm}$

Revolver al menos cuatro veces al dia

Permitir la extracción de aire húmedo al inicio del secado

\section{Caficultor:}

Para mantener la humedad del café utilice empaques exclusivos para café pergamino seco, dispóngalos en estibas protegidos del sol y en un cuarto ventilado. Consulte con su Extensionista.
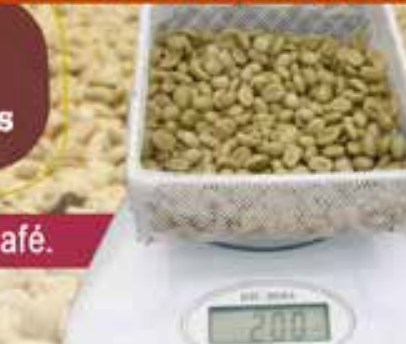

secado mecánico

Use Gravimet SM - secado mecánico

Temperatura máxima del aire: $50^{\circ} \mathrm{C}$

Caudal de aire óptimo: $0,1 \mathrm{~m}^{3} / \mathrm{min} / \mathrm{kg}$ de c.p.s.

Altura de capa: de acuerdo con el secador, la suma de las capas no debe ser mayor a $75 \mathrm{~cm}$

Invertir flujo de aire o capa cada 6 a 8 horas 


\section{Almacenamiento del café en finca}

Para mantener el café en el rango de humedad obtenido en el secado, es necesario disponer de unos requisitos mínimos de empaque y almacenamiento.

En los casos en los que se dispone de un lugar para realizar el almacenamiento en las fincas antes de llevar el café pergamino seco a la venta, deben tenerse en cuenta los siguientes aspectos:

- Los empaques utilizados deben ser nuevos o de uso exclusivo para café.

- El cuarto de almacenamiento debe estar ventilado y libre de humedad, además protegido del sol.

- Disponer de estibas para colocar el café y evitar el contacto con el piso.

- Los arrumes deben estar separados de la pared o ventanas para evitar rehumedecimientos.

> El lugar de almacenamiento debe estar libre de agroquímicos U otras sustancias que causen contaminación química al café.

\section{Determinación de la calidad del café}

El primer criterio para determinar la calidad física es el factor de rendimiento en trilla, que quiere decir, la masa de café pergamino seco necesaria (en kilogramos), para obtener un saco de $70 \mathrm{~kg}$ de café trillado excelso o tipo exportación.

Una vez el café ha pasado por el proceso de trilla se obtiene el café verde o en almendra. Para que un café se clasifique como excelso debe estar compuesto por granos principalmente plano-convexos, parejos, retenidos por encima de la malla 14, con tolerancia de hasta el $5 \%$ inferior a esa malla, pero retenido por la malla 12 , y por lo menos $50 \%$ de granos retenidos sobre la malla 15 . Los granos picados por broca por encima de 15 unidades son considerados defectos. Este criterio, además, permite determinar el precio interno de referencia, para el cual se toma como factor de rendimiento base 92,8 , obtenido 
de los kilogramos de café pergamino seco/70 $\mathrm{kg}$ de café trillado excelso). Este valor se publica diariamente en los puntos de compra, Cooperativas y Almacafé.

Para calcular el precio final $P_{c p s}$ se usa la siguiente expresión:

$$
P_{c p s}=\frac{f_{0}}{f_{r}} P_{0}
$$

Donde $f_{0}$ es el factor de rendimiento oficial que sale publicado diariamente en las Cooperativas del país, $P_{0}$ es el precio oficial del café con factor de rendimiento oficial y $f_{\mathrm{r}}$ el factor de rendimiento obtenido en la evaluación de calidad. El factor de rendimiento oficial $f_{0}$ normalmente es de 92,8 , sin embargo, en algunas ocasiones extraordinarias cuando la calidad del café es muy baja o hay coyuntura de precios, este factor toma el valor de 94,0.

El análisis sensorial, permite determinar la calidad en taza, un café de buena calidad debe tener como mínimo taza limpia, es decir, estar libre de defectos. La presencia de defectos en la taza, influencia el precio final porque se debe hacer un descuento de acuerdo con el tipo de defecto (I, II, III) y la frecuencia de tazas defectuosas por el total de tazas analizadas.

\section{Proceso de beneficio para cumplir con las siete prácticas}

El proceso que se utiliza para producir café, cumpliendo rigurosamente con las siete prácticas clave, se denominan 7P. Este proceso se presenta a continuación. 


\section{Prácticas clave para producir eaffe de huena ealitiad}
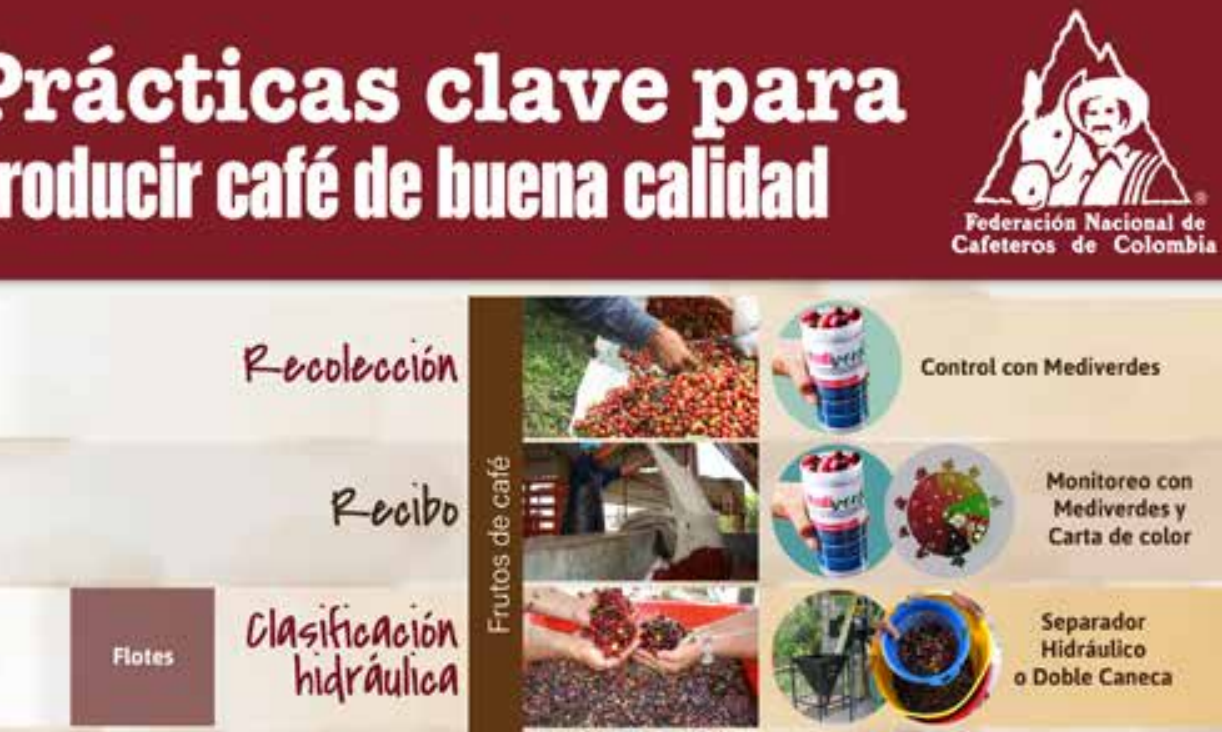

Clasificación hidraulica

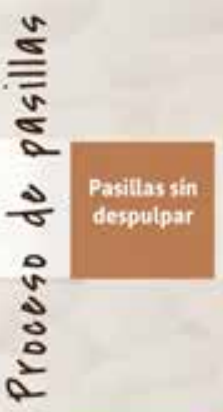

Despulpado sin agua

Clasificación por tamaño

\section{Remoción} del mucilago

Pasillas Clasificación Lavadas por densidad

Almacenamiento
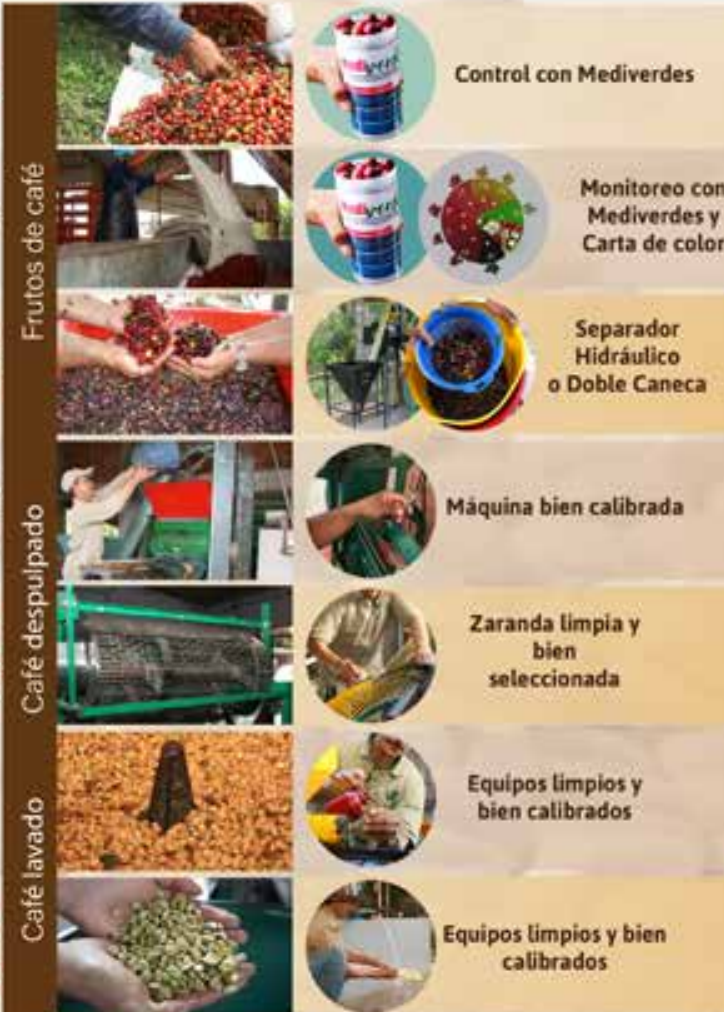

Zaranda timpia y bien

seleccionada

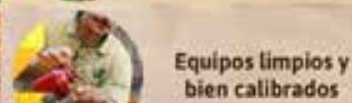

secado
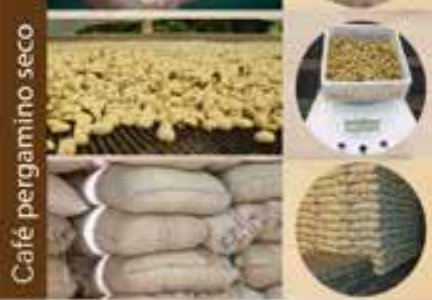

Monitoreo con

Gravimet SM o SS

Limpio, aireado

y sobre estibas

\section{Caficultor:}

Realice adecuada y oportunamente los procesos para cumplir If AGRONOMIA con las prácticas claves y producir café de buena calidad consulte con su Extensionista. 